\title{
The Application of Microbial Enhanced Oil Recovery in Chaoyanggou Daqing Low-Permeability Oilfield
}

\author{
Wu Xiaolin*,1,2, Hou Zhaowei ${ }^{2}$, Dou Xumou ${ }^{2}$, Li Wei $^{2}$, Wang Rui ${ }^{2}$ and Wu Xiaolei ${ }^{1}$ \\ ${ }^{1}$ College of Engineering, Peking University, Beijing 100871, China $;{ }^{2}$ Exploration and Development Institute of Daqing \\ Oil Field, Daqing 163712, China
}

\begin{abstract}
In order to develop the peripheral part of Daqing oilfield, one mixed bacteria system was screened and used for microbial flooding on Microbial Enhanced Oil Recovery (MEOR) process in Daqing low permeability oilfield where there are huge resource potentials but many disadvantageous conditions. From 2004 to 2009, Microbial flooding field test was conducted in Chaoyanggou oilfield. In 2004, Microbial flooding pilot test with 2 injectors and 10 producers was carried out. Seven out of 10 oil wells showed effective results, with 14.5 thousand tons of accumulative incremental oil. In October 2009, expanding field test with 9 injectors and 24 producers was carried out in the same block. By now, 15 oil wells have shown good effect. The daily oil production increased from 32.4 tons to 43.2 tons and the incremental oil amounts to 9370 tons. The microbial flooding results showed that wells along the main channel sand and developed fracture zones had a better response.
\end{abstract}

Keywords: Low permeability reservoir, microbial enhanced oil recovery, microbial flooding, Chaoyanggou oilfields.

\section{INTRODUCTION}

Low permeability reservoir has the characteristics of low porosity, low natural productivity, bad physical property of reservoir, and even little oil in the condition of conventional oil extraction. Traditional technique of water flooding can easily lead to the continuous rise of injecting pressure, insufficient feed flow of a producing well, fast decline of production, low oil-production rate, and so on. At the same time, many mature techniques used in EOR have been restricted by the low mobility of crude oil, small reservoir thickness and weak formation [1-6]. A number of researchers have focused on the huge but difficult-to-exploit resource and looking for good ways to exploit them. Presently, MEOR(microbial enhanced oil recovery)has become an important topic for the development of low permeability Daqing oilfield, except for the methods of injecting water, formation of hydraulic fracturing and acid treatment.

\section{STRAINS SCREENING AND PERFORMANCE EVALUATION}

A group of Brevibacillus brevis and Bacillus cereus were screened and studied. The results show that both Brevibacillus brevis and Bacillus cereus are rod-shaped with a cell size from $0.8 \times 1.2-1.6 \mu \mathrm{m}$ and $0.4 \times 0.8-1.2 \mu \mathrm{m}$, respectively, and able to generate non-circular gemmas. Their colonies are milky white and moist with a diameter from 0.2 to $0.4 \mathrm{~mm}$ and 0.6 to $1.0 \mathrm{~mm}$, respectively.

*Address correspondence to this author at the College of Engineering, Peking University, Beijing 100871, China; Tel: 86-0459 5508 647;

E-mail: wuxldq@petrochina.com.cn

\subsection{Compositional Change of Saturated Hydrocarbons in the Crude Oil Before and After Microbial Treatment}

The hydrocarbons were separated from the oil before and after microbial treatment and were analyzed with gas chromatography. The analysis demonstrates that the composition of these saturated hydrocarbons in treated crude oil is distinctly different from those found in the blank oil. The long-chain alkanes are biodegraded by the two microbes, resulting in a decrease in heavy component content and an increase in light component content, which can be determined on the basis of the index of $\Sigma \mathrm{C} 21-/ \Sigma$ $\mathrm{C} 22+$ and $\mathrm{C} 21+\mathrm{C} 22 / \mathrm{C} 28+\mathrm{C} 29$. Additionally, the decrease of OEP indicates the degree to which the ripeness of the crude oil is improved. Ratios of $\mathrm{Pr}, \mathrm{Ph}$ and $\mathrm{nC} 12 \sim$ nC18 alkanes had no change before and after microbial treatment. Therefore, it can be concluded that only long chain alkanes (> C20) can be degraded, with no evidence of short-chain alkane (less than C20) degradation found. Meanwhile, no short-chain alkanes are generated during the alkane biodegradation process.

\subsection{Changes in Viscosity, Wax Content and Gum Content}

The viscosity, wax and gum content of treated oil are measured after dehydration by centrifugalization under low temperature. Viscosity, wax, and gum content found to be decreased by $40 \%, 1.3-4.9 \%$ and $0.7-1.2 \%$, respectively.

\subsection{Changes in Fermentation Liquor's Interfacial Tension and Ccontent of Organic Acid}

Interfacial tensions (IFT) between fermentation liquor and oil before and after culture were measured and the result showed that IFT dropped by about $50 \%$ after culture. Active 


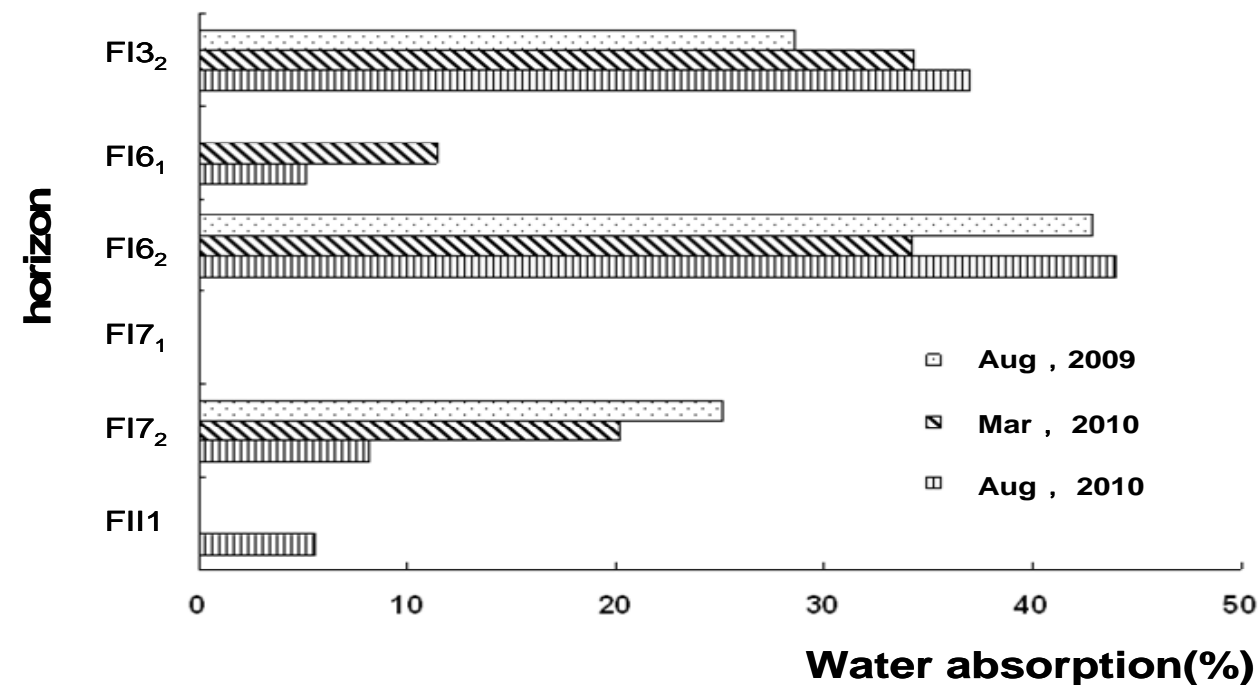

Fig. (1). Change of water injection profile about well Chao62-122 before and after microbial flooding.

substances which are favorable for reducing interfacial tension were generated.

Contents of organic acid before and after culture were measured. The results showed that two microbes can produce different organic acids. This characteristic can contribute to permeability improvement in less-permeable reservoirs.

Low molecular-weight organic acids and alcohols in two fermentation liquors of Bacillus cereus and Brevibacillus brevis were qualitatively and quantitatively analyzed by GCMS. Four organic acids, acetic acid, propionic acid, butyric acid and isovaleric acid and one alcohol, ethanol were detected in the Bacillus cereus fermentation liquor, while three organic acids - acetic acid, propionic acid and butyric acid-were found in the Brevibacillus brevis fermentation liquor.

\section{OVERVIEW ABOUT THE BLOCK OF THE MICROBIAL FLOODING FIELD TEST}

The block of microbial flooding test is located in Chaoyanggou anticline axis area belonging to the central of Songliao basin reservoir named Chao 50, whose main development layer is Fuyu formation, which is fluvial facies deposition. The strata temperature is $55^{\circ} \mathrm{C}$ and the original formation pressure is $8.5 \mathrm{MPa}$, the average air permeability of reservoir matrix being $25 \times 10-3 \mu \mathrm{m} 2$, with effective porosity $17 \%$, as well as the original oil saturation is $57 \%$.

In June 2004, the pilot field test of microbial flooding was carried out and a good effect was observed with the total amount of incremental oil production as $1.45 \times 104$ tons. An enlarged microbial flooding field test was carried on at the same block in November 2009, with 9 injection wells and 24 producing well.

\section{THE EVALUATION ON THE EFFECT OF THE FIELD TEST}

\subsection{Design for the Project of Microbial Flooding}

\subsubsection{Microbial Flooding Pilot Test of Chao 50 Oilfield}

The complete dosage of microbial culturing fluid was designed in $100 \mathrm{mg} / \mathrm{L} \cdot \mathrm{PV}$ (Pore Volume), amounting to 250.4 tons, which was injected in two cycles, averaging of 125.2 tons in each cycle.

\subsubsection{The Enlarged Microbial Flooding Test}

The enlarged field test has been designed using microbial culturing fluid $(600 \mathrm{mg} / \mathrm{L} \cdot \mathrm{PV})$ amounting to 2100 tons, which was injected in three cyclesaveraging dosage of 700 tons in each cycle.

\subsection{The Characteristics of the Dynamic Response}

\subsubsection{The Injection Profile has been Improved Effectively}

Due to the interlayer differences of water absorbing capability, a large number of microbes will move into the strong water or high water-out layer firstly, influencing the corresponding producing wells with high water cut. The method of separated layer microbial flooding has been used in this test. By contrast with the data of injection profile before and after microbial flooding, we found that the profile has been improved. At the same time, the oil recovery has been enhanced. See Fig. (1).

\subsubsection{Oil Displacement Resistance and Injection Pressure Dropped}

The injection pressure has been reduced and the quantity of injected water increased in the pilot field test. See Fig. (2). The injection pressure of well Chao 61-Y123 dropped from 11.6 $\mathrm{MPa}$ before microbial flooding to $8.8 \mathrm{MPa}$ at the end of first cycle, then the injection pressure rose up to $11.7 \mathrm{MPa}$ gradually until the second cycle begun, with the injection pressure dropped again in the course of the second microbial flooding cycle.

The variation of injection pressure reflects the mechanism of MEOR mentioned above. The displacement resistance is affected by pore size, oil-water interfacial tension and viscosity of crude oil, etc. Displacement resistance has been declined after microbe injection, showing the bacteria screened have changed the interfacial tension between oil and water, oil viscosity and water injection pressure. 


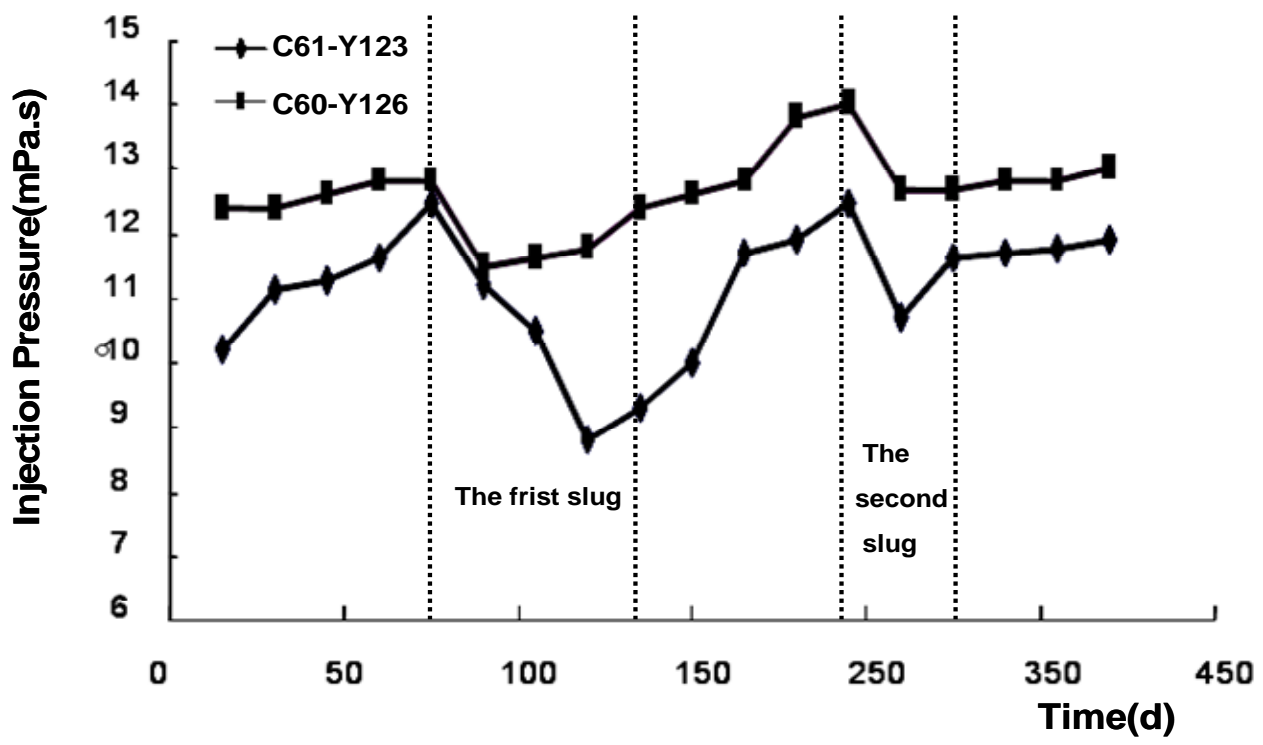

Fig. (2). Change of well injection pressure before and after microbial flooding.

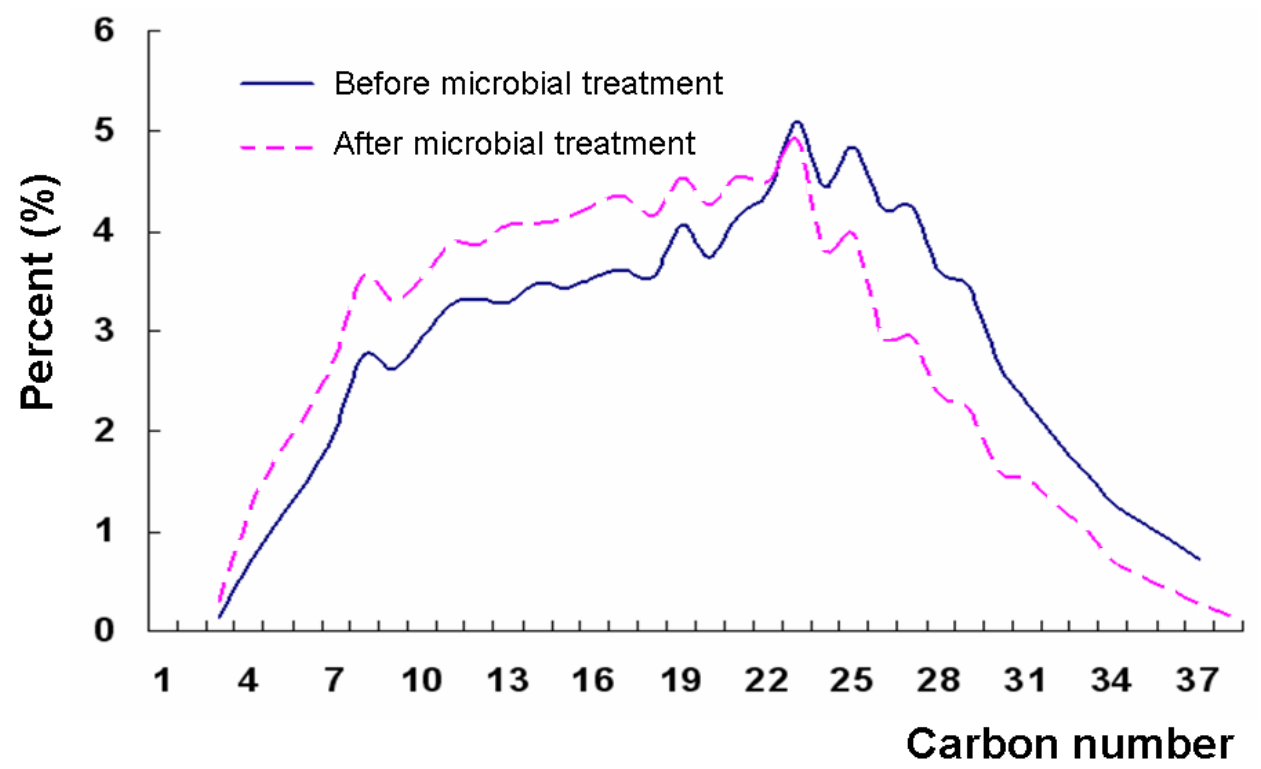

Fig. (3). Change of alkane component in the crude oil of well 61-Y-121 before and after microbial flooding.

\subsubsection{Chosen Bacterium has Ggood Adaptability to Reservoir Conditions and Can Grow and Metabolize}

The change of bacterium concentration in produced liquids is one critical index to measure if bacterium chosen for oil recovery may adapt to reservoir conditions and grow or reproduce under the formation.

Test results of bacterium concentration in produced liquid before and after microbe injection indicate that, microbial concentration has increased $1 \times 10^{2}$ cells per milliliter or more than former. It shows that microbe has reached oil well through layers. Bacterium concentration injected on spot was about $10^{7}$ cells per milliliter and that of oil well with good response maintained at $10^{6}$ cells per milliliter, indicating that microbes reproduce within the reservoir. No microbe was tested or found for 2 nonresponsive wells.

\subsubsection{Bacteria may Degrade Heavy Components of Crude Oil, Produce Active Materials}

Comparison before and after test indicates that the average viscosity of crude oil from three oil wells declined from $94.3 \mathrm{mPa} \cdot \mathrm{s}$ to $76.0 \mathrm{mPa} \cdot \mathrm{s}$, which showed injected microbes had caused selective degradation of heavy component contents of oil formation and the rise of light component contents relatively. See Fig. (3). Additionally, wax content decreases from $12.4 \%$ to $7.6 \%$ and the gum content decreased from $17.5 \%$ to $13.6 \%$. The decrease of wax content or gum content in crude oil can improve oil properties and water injection, and it will also help oil well to restore normal production and lessen the application of other stimulation treatments, for example, hot water washing or acidizing. Moreover, the solidifying point of the crude oil declined from $40^{\circ} \mathrm{C}$ to $35.7^{\circ} \mathrm{C}$, improving the flow capacity of the crude oil. The interfacial tension between oil and 


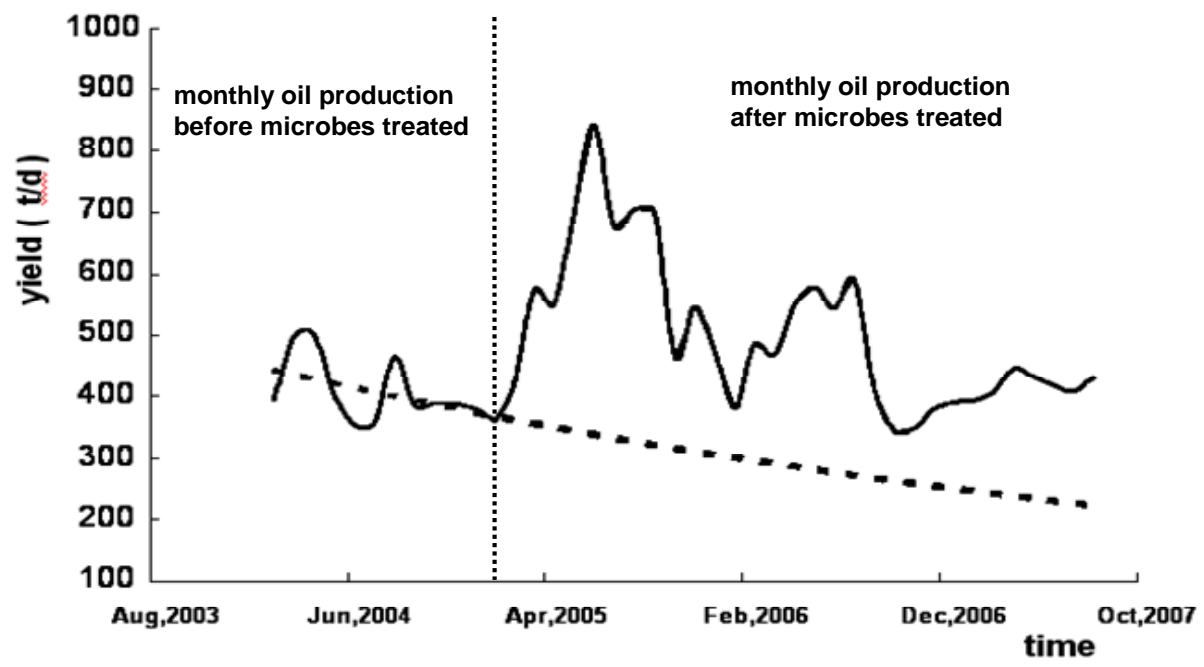

Fig. (4). Change of oil production before and after microbial flooding pilot test.

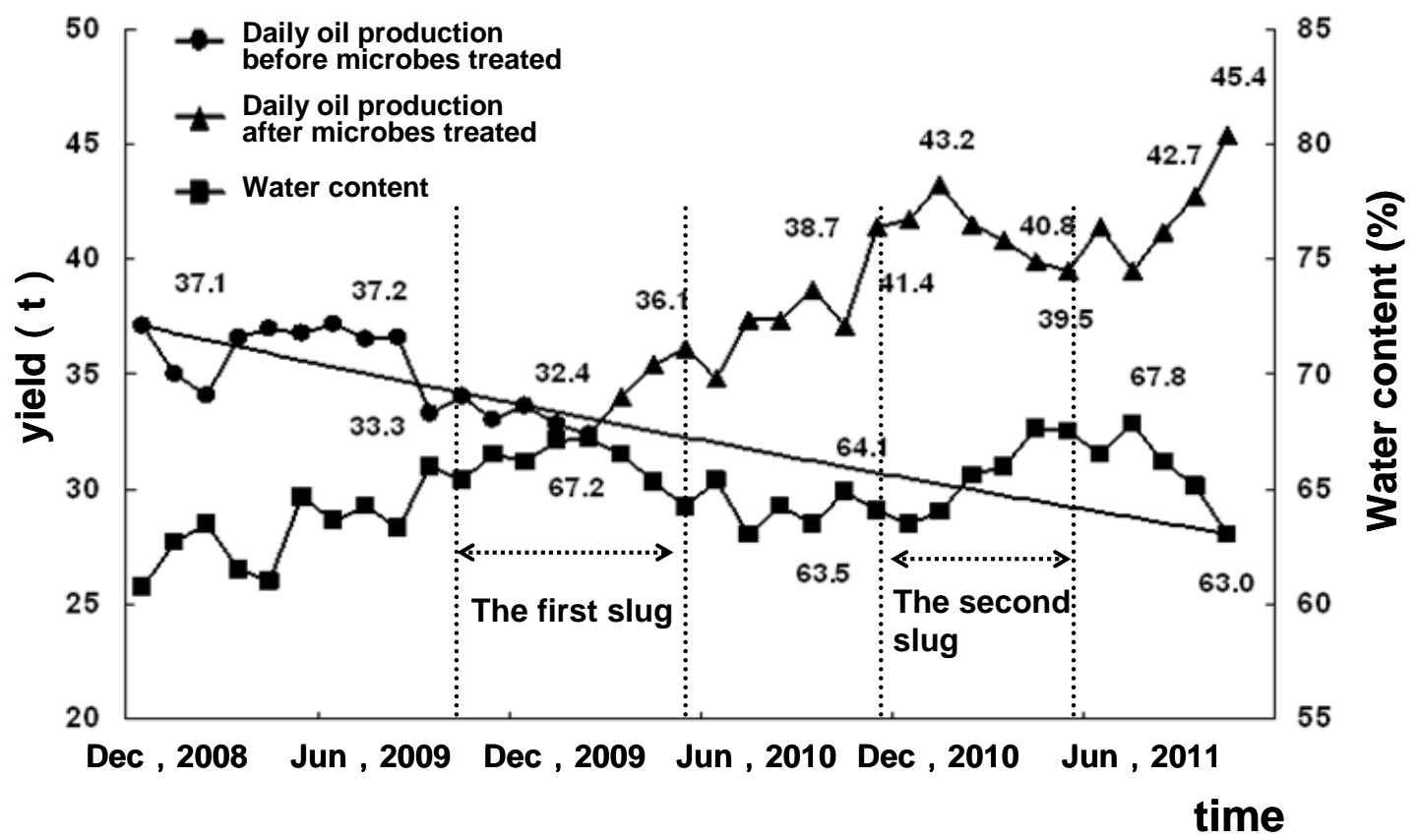

Fig. (5). Change of oil production before and after microbial flooding expanding field test.

water decreased by $6.5 \mathrm{mN} / \mathrm{m}$ from $46.3 \mathrm{mN} / \mathrm{m}$ to $39.8 \mathrm{mN} / \mathrm{m}$ which suggested that under reservoir conditions microbial metabolism produced active materials primarily composed of bio-surfactant.

\section{THE EFFECT ANALYSIS OF TEST FIELD}

\subsection{Oil Production Increase and Water Cut Decrease Show a Good Effect}

\subsubsection{The Pilot Field Test of Chao 50 Microbial Flooding}

Seven among ten oil wells had responses by the end of July 2009. Monthly liquids production increases from $957 \mathrm{t}$ to 1456t, water cut decreased from $46.8 \%$ to $40.3 \%$, monthly oil production increases from 361 t to 843 t (see Fig. 4). The accumulative oil increment is 14.5 thousands tons.

\subsubsection{The Enlarged Field Test of Chao 50 Microbial Flooding}

Based on the pilot test field, an enlarged test was carried out in October 2009, at the same block with 9 injection wells and 24 oil production wells. By the end of October 2011, 15 oil wells had responses and the daily oil production increased from 32.4 tons to 45.4 tons. The accumulated oil increment is 9.37 thousands tons. See Fig. (5).

\subsection{The Relation Between Injection and Production is the Main Factor Influencing Microbial Flooding Effect}

Four wells with good responses are located in the main development layer F132, while two wells on different location have no response. Analysis of injection profile indicates that layer F132 has the highest water absorbing capacity. Injected microbe mainly enters into layer F132, and 


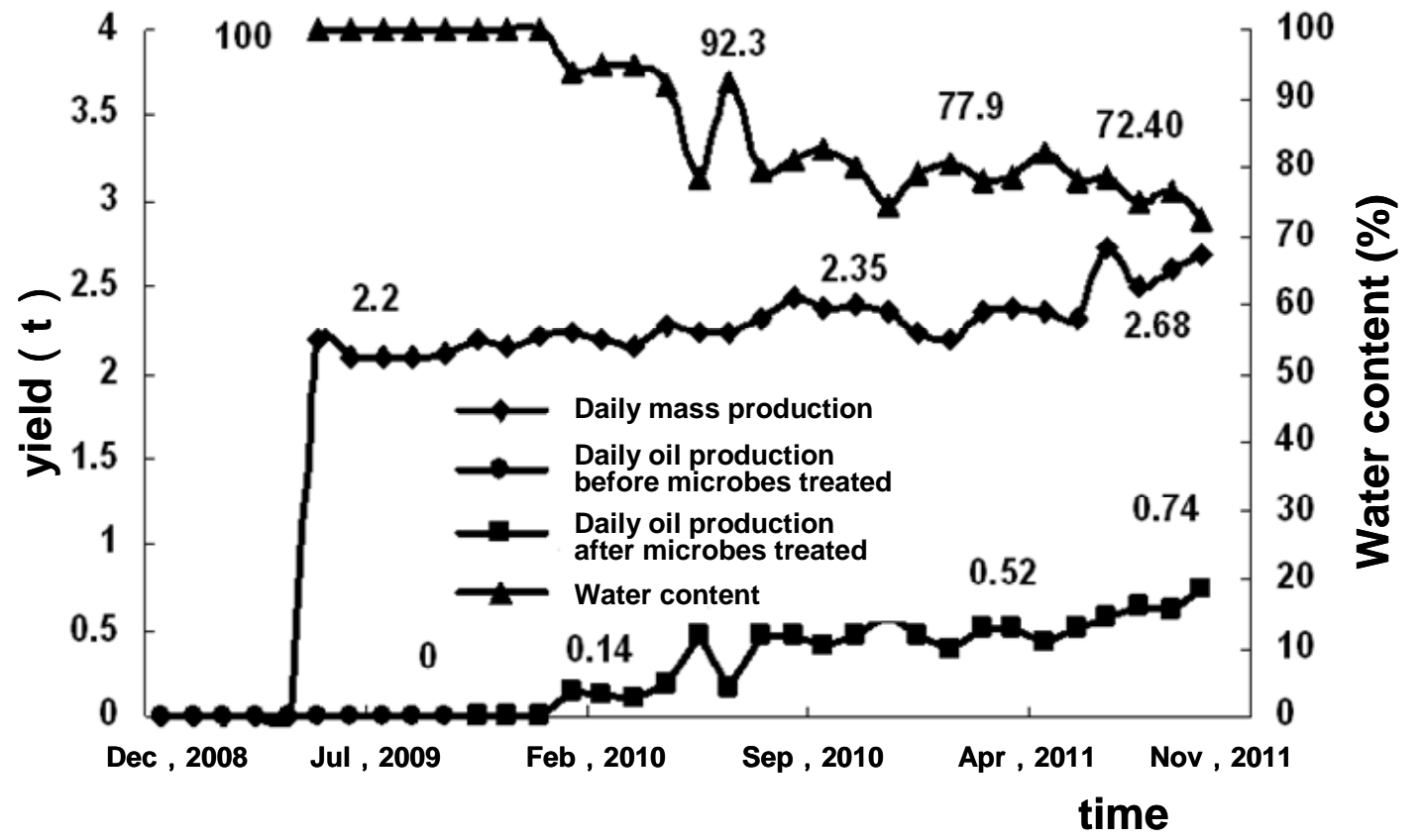

Fig. (6). The production performance curve of well 60-124.

advance along the waterline. For the enlarged field test, the same result that 7 oil wells located in the main channel sandbody and in the direction of fracture had the most productive responses was observed in October 2009. However, for the oil wells located in the direction with developed fissures, such as Well 58-126 and Well 58-128 or wells having low water cut, poor water absorbing capability and imperfect relation between injection and production, it is difficult for microbes to enter mainly into the layers with good absorbing capability.

\subsection{MEOR Contributes to the Establishment of Effective Driving System}

Start-up pressure exists in low permeability reservoirs and only when the driver differential pressure is higher than start-up pressure, the water flooding control reserves can be effectively spent. Well $60-124$ among the producers in the test block had been closed for 3 years because of no liquids production before microbial injection. After 3 months of microbial injection, well 60-124 was opened and its liquids production and oil production maintained above 1.0t and $0.2 t$, respectively. The startup of the exhausted well indicates that MEOR technology contributes to reduce filtrational resistance during water flooding, drive bypassed oil in exhausted wells and improve displacement characteristic, showing that microbes contribute to build effective driving system in oil layers. See Fig. (6).

\section{CONCLUSION}

(1) Two strains of bacteria, Brevibacillus brevis and Bacillus cereus, were screened from Daqing produced water. The study showed that after microbial treatment, the viscosity of crude oil declined by $40 \%$ and wax content and gum content dropped to varying degrees.

(2) Screened microbes have good adaptability with low permeability and the concentration of microbes can produce active substances in the reservoir, resulting in the decrease of the oil viscosity, wax content and gum content and the improvement of rheological behavior of crude oil. At the same time, an effective startup pressure has been formed due to the microbial flooding.

(3) The accumulative oil increment was 14.5 thousands tons and the term of validity had passed over 3 years after microbial injection, indicating that a good result of MEOR can be obtained even if the permeability is below $25 \times 10^{-}$ ${ }^{3} \mu \mathrm{m}^{2}$.

(4) The connectivity of reservoir can affect the result of MEOR obviously and the reservoir with developed fracture can be helpful to MEOR. Therefore, a good effect on field test can be acquired by combination of MEOR and fracturing treatment.

\section{CONFLICT OF INTEREST}

The authors confirm that this article content has no conflicts of interest.

\section{ACKNOWLEDGEMENT}

Declared none.

\section{REFERENCES}

[1] P.K. Sharma, and M.J. Mclnerney, "Effect of grain size on bacterial penetration, reproduction, and metabolic activity in subsurface porous materials", Applied \& Envionmental Micobialogy., vol. 60, no. 5, pp. 1481-1485, 1994.

[2] Y. Xujun, Y. Xiaoduan, B. Wei, Z. Jing, H. Jin, and Z. Hongtao, "Difficulties and countermeasures on low permeability reservoir development", Drilling \& Production Technology, vol. 29, no. 4, pp. 31-33, 2006

[3] C. Huaqing, "Development technology and its application in low permeability oil and gas fields in the peripheral part of Daqing", Petroleum Geology \& Oilfield Development in Daqing, vol. 19, no. 5, pp. 1-3, 2000. 
[4] L. Li, and H. Dejin. "Development technique of outlying low permeability pools of Daqing oilfield", Petroleum Geology \& Oilfield Development in Daqing, vol. 23, no. 5, pp. 85-87, 2004.

[5] W. Xiuyuan, "The study on MEOR", Microbiology, vol. 26, no. 5, pp. 383-385, 1999.
[6] W. Weidong, W. Zhu, and G. Xueli, "The effect analysis of application on MEOR in America", Petroleum Geology And Recovery Efficiency, vol. 9, no. 6, pp. 74-76, 2002.

Received: March 06, 2012

Revised: June 11, 2012

Accepted: June 28, 2012

(C) Xiaolin et al.; Licensee Bentham Open.

This is an open access article licensed under the terms of the Creative Commons Attribution Non-Commercial License (http://creativecommons.org/licenses/by-nc/3.0/) which permits unrestricted, non-commercial use, distribution and reproduction in any medium, provided the work is properly cited. 